\title{
Personality And IT Project Team Makeup
}

Melinda L. Korzaan, Middle Tennessee State University

Stanley E. Gambill, Middle Tennessee State University

\begin{abstract}
IT project success continues to present major problems for organizations. The CHAOS survey results for 2004 report that only 29\% of IT projects were considered successful, 53\% were challenged, and 18\% were considered failures. Many of these problems are avoidable and it is important to understand the various success factors associated with IT projects. This study provides insight into improving these inadequate IT project outcomes by investigating the influence of IT project team member personality traits on project success factors. The "Big Five" factor model of personality is utilized to measure team member personality characteristics. Relationships between the Big Five personality traits and the project success factors of "on schedule" and "quality" are evaluated. Results indicate the personality trait of extroversion is positively associated with keeping the project on schedule, while the trait of openness to experience is negatively associated with keeping the project on schedule. In addition, conscientiousness was found to have a positive influence on project quality. Agreeableness was not evaluated and no significant relationship was found between emotional stability and project success.
\end{abstract}

Keywords: Systems Development, Project Management, Personality Theory

\section{INTRODUCTION}

C n general, the business community would prefer to see higher success rates for Information Technology (IT) related projects. Companies are investing large sums of money in IT projects only to witness many of these projects ultimately fall short of their expected benefits. Failures continue to plague IT projects at an unacceptable rate, and "underperformance on IT projects represents a considerable but, to a large extent, avoidable loss of economic value" (Calisir and Gumussoy, 2005, p. 631). The Standish Group has been tracking IT's dismal project performance in their Chaos Reports since 1994 when only $16 \%$ were considered successful, 53\% were challenged and $31 \%$ were outright failures. Performance has not improved significantly with 2004 results showing $29 \%$ successful, $53 \%$ challenged, and $18 \%$ failed (Hartman, 2006). TATA Consultancy Services provide further evidence of problems in their 2007 study that indicates 1 in 3 IT projects fail and $43 \%$ of organizations surveyed accept problems as the norm. Common problems were identified as time overruns (62\%), budget overruns (49\%), and higher than expected maintenance costs (47\%) (TATA, 2007). This study attempts to provide insight into improving these dismal IT project statistics by investigating the influence of IT project team personnel on project success factors.

The human resource element has historically been, and continues to be, of significant interest to the IT community. It is well-known in the literature that a key challenge facing IT managers is acquiring and developing their personnel. This includes the process of selecting the right people to participate in IT projects (White, 1984). The main purpose of this study is to investigate the relationship between project team members' personality traits and project outcomes. The research question is: can we improve project outcomes by selecting the right people for the right roles in project teams? To date, there have been few studies addressing the connection between individual personality traits of IT team members and IT project success. In the domain of IT, only one study was found that related individual team member traits to project outcomes (White, 1984). White contributed to the IT literature by investigating the association between individual cognitive styles, based upon the Myers-Briggs Type Indicator (MBTI), and team outcomes. White concluded, based upon a case study investigation, that a variety of cognitive styles is beneficial in the composition of an IT project team. This study is distinct from White's work in that it is an 
empirical analysis, and thereby provides the ability to statistically predict project outcomes. Another distinguishing factor between this study and previous research is that this study incorporates a prevalent framework from the psychology literature for personality, which is the five-factor model of personality (McCrae and Costa, 1987). Therefore, this study expands upon previous research by utilizing the Big Five personality model to predict and explain IT project outcomes.

\section{LITERATURE REVIEW AND HYPOTHESES}

\section{Project Success}

The two project success factors assessed in this study are "on time" and "quality". Traditional measures of project success, both in the IT domain and for projects in general, include the triangle of cost (budget), time (schedule), and functionality (quality) (Schwalbe, 2005; Wateridge, 1998; Gardiner and Stewart, 2000). While controlling costs and remaining within the budget is an important aspect of IT project management, it exceeds the scope of this study. Budgets are typically controlled by upper management and the project team members themselves are not likely to have a significant influence on budgetary decisions. Therefore, it is unlikely that team member personality traits would be significantly related to whether costs are kept within budget.

\section{The Five-Factor Model of Personality}

The five-factor model of personality, also known as the Big Five, is a framework that classifies human personality into five general areas. These classifications include agreeableness, extraversion, openness to experience, conscientiousness, and emotional stability (Gosling, Rentfrow, and Swann Jr., 2003). The five-factor model was chosen for this study for two main reasons. First, this personality model has received considerable attention both theoretically and empirically in the psychology literature. In addition, there has been a significant amount of research linking the Big Five to job performance in a variety of domains including sales, management, and customer service (Hurtz and Donovan, 2000; Salgado, 1997). This research escorts the Big Five to the field of Information Technology and investigates how well the relationship between personality traits and performance travels to the IT domain. The discussion below presents descriptions of each personality trait and develops the hypotheses. The proposed model is shown in Figure 1.

\section{Agreeableness}

Individuals high in the agreeableness personality dimension are mostly interested in interpersonal relationships. They are thought of as being kind, considerate, likable, friendly, cooperative, and warm (Moberg, 2001; Seibert and Kraimer, 2001). In general, agreeableness has not been found to have a significant influence on task performance with the exception of a moderately positive influence on performance in certain jobs that center around interpersonal facilitation (Hurtz and Donovan, 2000; Moberg, 2001). Because there is a lack of evidence relating agreeableness to other job-related performance criteria, agreeableness is not hypothesized to influence either project schedule or project quality.

\section{Extraversion}

Extraversion is characterized by individuals who are energetic and enthusiastic. Extraversion has been shown to be positively related to transformation leadership in team activities for the Singapore armed-forces. Transformational leadership includes attributes such as inspirational motivation (Linn and Ployhart, 2004). This motivational aspect of extraverts along with their high energy level would likely induce the drive to "get things done" and in turn may influence extraverts' ability to keep workflow moving to accomplish tasks within a scheduled timeframe. Therefore, it is hypothesized that extraversion will be positively related to remaining on schedule. There does not seem to be consistent evidence, though for supporting a hypothesized relationship between extraversion and quality (Salgado, 1997). Therefore, a relationship is not proposed to exist between extraversion and quality. 
H1: Extraversion will be positively related to remaining on schedule.

Openness to Experience

Openness to experience is associated with individuals who are creative, intellectually complex, artistic, curious, imaginative, flexible, and have a strong need to experience variety (Moberg, 2001; Seibert and Kraimer, 2001; Barrick and Mount, 1991). Because individuals high in the openness to experience trait have a tendency to procrastinate (Watson, 2001) it is likely that openness to experience will be connected to schedule overruns. Therefore it is hypothesized that the openness to experience will be negatively related to remaining on schedule.

H2: Openness to experience will be negatively related to remaining on schedule.

\section{Conscientiousness}

Conscientiousness is the most consistent and valid traits linked to overall job performance across a variety of work environments and performance measures (Hurtz and Donovan, 2000). Conscientious individuals are typically dependable, persistent, hardworking, and achievement oriented. In addition they are known to be responsible, planning-oriented, and organized (Barrick and Mount, 1991). These attributes logically explain why conscientiousness has been consistently associated with positive work-related outcomes. It is believed that the solid work ethic of conscientious individuals will be associated with higher IT project quality. In addition, due to the organization skills and the planning nature of conscientious individuals, it is believed that conscientiousness will lead to projects remaining on schedule. Therefore, it is hypothesized that conscientiousness will be positively related to both schedule and quality.

H3: Conscientiousness will be positively related to remaining on schedule.

H4: Conscientiousness will be positively related to quality.

\section{Emotional Stability}

Individuals who are emotionally stable are more likely to experience positive emotions and are less prone to experience negative emotions such as fear, sadness, anxiety, moodiness, and jealousy. In addition, emotionally stable individuals are more apt to be relaxed, able to control impulses, and capable of effectively coping with stressful situations (Moberg, 2001; Seibert and Kraimer, 2001). Although all studies have not consistently associated emotional stability with job performance, according to Salgado's (1997) meta-analysis, it was concluded that overall emotional stability was a valid predictor of job performance. Therefore, it is hypothesized that emotional stability will have a positive influence on both project schedule and quality.

H5: Emotional Stability will be positively related to remaining on schedule.

H6: Emotional Stability will be positively related to quality. 
Figure 1: Proposed Model

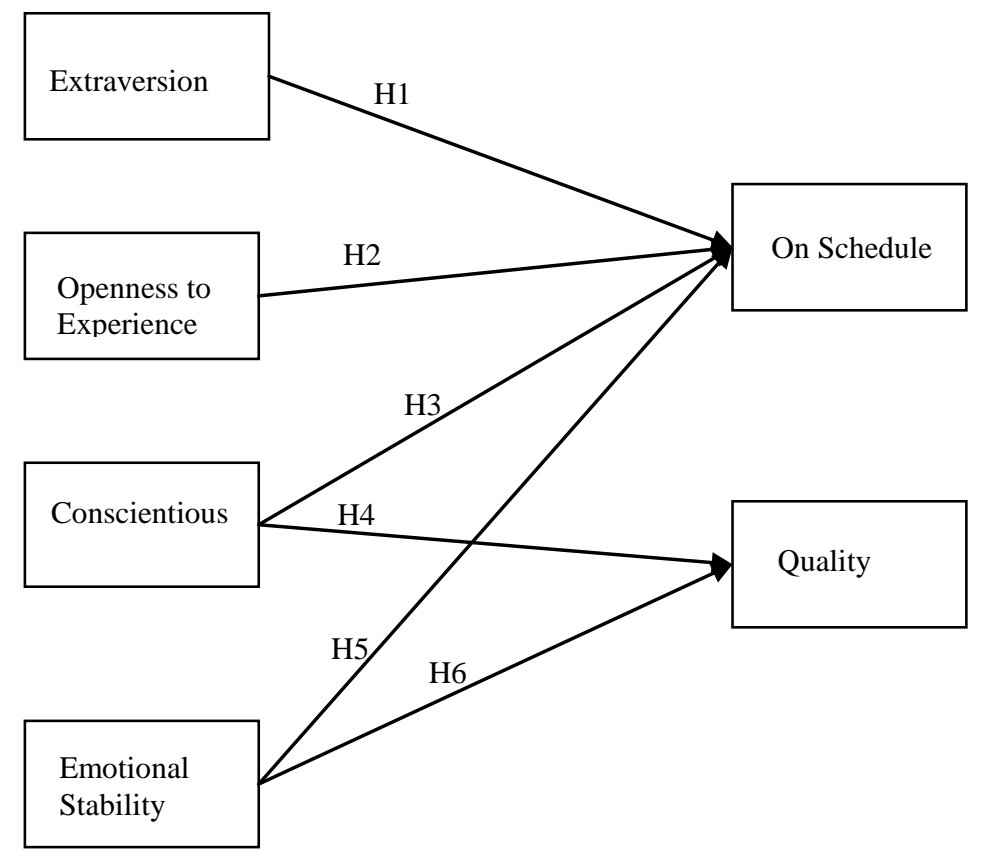

\section{METHOD}

The data for this study was collected via an online survey administered to professionals involved in IT projects. The sample targeted for this study was project team members, and questionnaire items used in the survey were adapted from existing measures. Items capturing perceptions of information system project outcomes (schedule and quality) were adapted from Barki and Hartwick (2001). Items assessing personality traits were used from Gosling, Rentfrow, and Swann's (2003) study, which validated a short-form measure for the Big Five personality traits. This short-form was selected for measuring personality characteristics for the distinct purpose of keeping the survey instrument brief. One drawback of conducting Big Five personality research in the past has been the lengthy survey instruments required to measure the personality dimensions. Such instruments ranged from 40 to 240 questions. This is especially problematic for researchers conducting field research. In today's fast-paced and demanding business environment, actual practitioners do not have time to complete lengthy surveys. Researchers are in need concise, validated measures when gathering data from IT workers in order to maximize the efficiency of data gathered while still respecting the tight time constraints of practitioner participants. Furthermore, the traditional, time-consuming survey instruments may be one reason why historically Big Five personality research has not been conducted in the IT field. Based upon the above reasoning, it was determined that the Gosling, Rentfrow, and Swann's (2003) validated measure comprising of only 10 questions would be ideal for this study. Overall, the brief 10-question survey is a benefit not only for researchers but also for managers, who may be more inclined to utilize personality measures in business when the survey is concise and doesn't require much time to administer. The survey items are shown in Appendix A. The survey data collected was then analyzed using Structural Equation Modeling (SEM) with AMOS as the statistical tool. Results from validity assessment and hypothesis testing are discussed in the following section.

\section{RESULTS}

A total of 232 survey responses were gathered consisting of 59.9\% male and $40.1 \%$ female respondents. The typical survey participant was between 40 and 49 years old (44.4\%), had attained a four-year college degree (59.9\%), had an average of 9.92 years work experience in IT, and had been employed at his/her current organization 
for 9.8 years. Validity and reliability was assessed for the Big Five measures. It is noted that reliability and correlates are by nature less strong for short measures than they are for longer measures (Gosling, Rentfrow, and Swan, 2003; Kline, 2000; Wood and Hampson, 2005). Therefore, it is not alarming that alphas for openness to experience $(\mathrm{alpha}=.45)$, conscientiousness $(\mathrm{alph} a=.51)$, and emotional stability (alpha $=.56)$ were below the standard threshold, with only extraversion (alpha $=.73$ ) attaining an alpha value above .70 . Although psychometrics are somewhat inferior to traditional Big Five measures, there is still a high degree of confidence in the validity of the 10-item scale used in this study. Gosling, Rentfrow, and Swan (2003) conducted rigorous testing in their original validity study including test-retest reliability, convergence across other Big-Five measures, and patterns of external correlates. Furthermore, additional empirical studies of the 10-item measures have recently been conducted and conclusions concur that the measures are psychometrically solid, useful, and sufficient for research settings especially in situations where time constraints exist (Donnellan, Oswald, Baird, and Lucas, 2006; Rammstedt and John, 2007). Therefore, due to the merits of pre-existing validity studies and because the intentions of this study was to use a practical measurement instrument that would be well suited for participants from industry with tight time constraints, it is concluded that the Gosling, Rentfrow, and Swann instrument is appropriate and valid for the current study.

Three of the six hypotheses were supported. A summary of the hypothesis testing results are shown in Table 1. The resulting model, with standardized coefficients and $\mathrm{R}^{2}$ values, is shown in Figure 2. Extraversion was verified as having a positive influence on the project schedule, while openness to experience was confirmed to have a negative influence on the project schedule. Conscientiousness had a positive influence on project quality; however, the proposed relationship between conscientiousness and project schedule was not supported. There are two possible explanations for the non-significant finding for the relationship between conscientiousness and project schedule. First, because conscientious individuals are focused on producing quality work, they may be willing to sacrifice time for quality. In other words, conscientious individuals may be motivated by perfectionism to the extent that they see quality as a more important goal than keeping on schedule and therefore may be more willing to sacrifice the project schedule in order to ensure quality. Another possible explanation may be the existence of intervening variables.

Neither hypothesis for emotional stability was supported. Therefore, emotional stability was not found to have a significant influence on either project schedule or quality. Once again, the presence of intervening variables may explain these non-significant findings regarding emotional stability. Identifying such variables influencing the relationship between emotional stability and project success factors would be a desirable goal for future research studies. Another plausible explanation may be that perhaps the relationship between emotional stability and project success factors is non-linear (Salgado, 1997).

The R-square values show a moderate explanation of the dependent variables, with $5 \%$ of the variance explained in the schedule dependent variable and $8 \%$ of the variance explained in the quality dependent variable. The magnitude of these values is consistent with R-squares found in other personality research (Hurtz and Donovan, 2000; Judge, Martochhio, and Thoresen, 1997).

Table 1: Hypothesis Testing

\begin{tabular}{|l|c|c|c|c|}
\hline Hypothesis & $\begin{array}{c}\text { Standardized } \\
\text { Beta }\end{array}$ & T-value & P-value & Conclusion \\
\hline H1: Extraversion -> Schedule & .15 & 2.17 & .030 & Supported \\
\hline H2: Openness -> Schedule & -.20 & -2.69 & .007 & Supported \\
\hline H3: Conscientious -> Schedule & .13 & 1.91 & .057 & Not Supported \\
\hline H4: Conscientious -> Quality & .26 & 3.9 & $<.001$ & Supported \\
\hline H5: Emotional Stability -> Schedule & .06 & .89 & .372 & Not Supported \\
\hline H6: Emotional Stability -> Quality & .06 & .84 & .404 & Not Supported \\
\hline
\end{tabular}




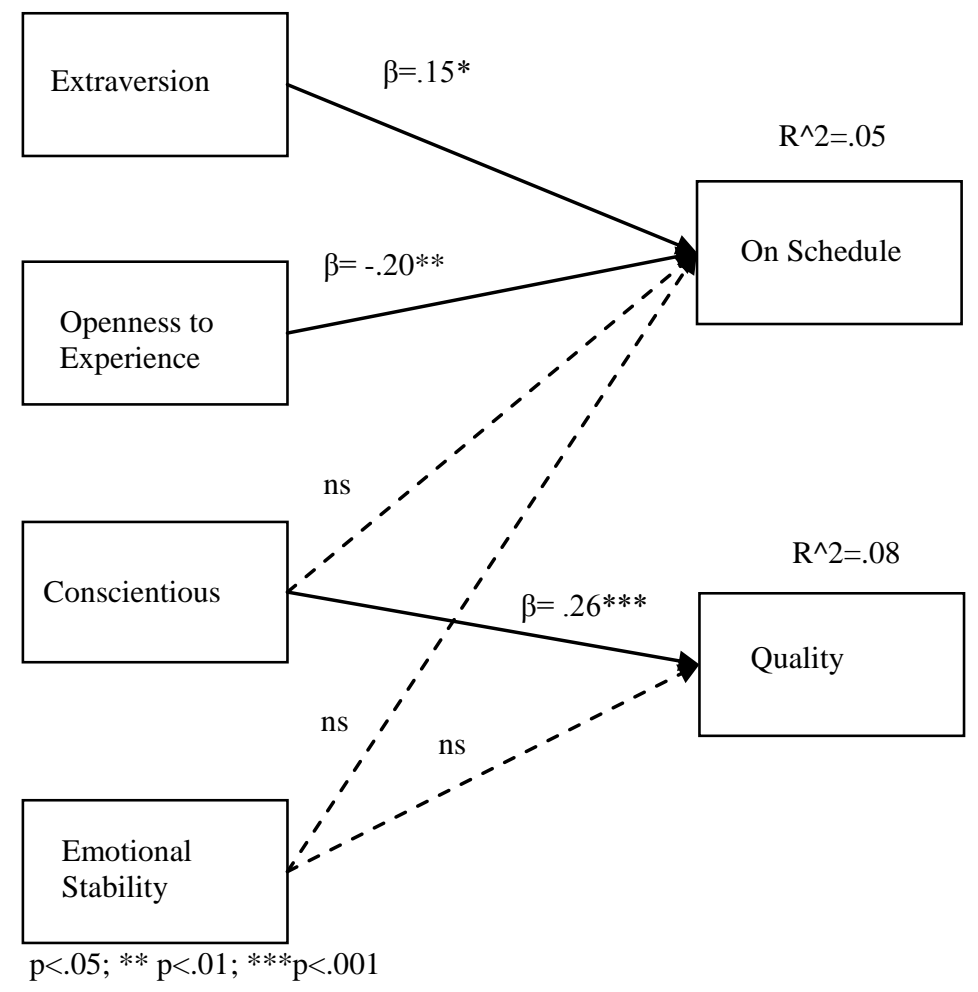

\section{DISCUSSION}

This study provides a contribution to both practitioners and theory. For researchers, this study provides a theory-based model that explains and predicts IT project success factors by examining individual personality traits. This study fills a gap in the existing IT literature by providing a theoretical basis for examining the human resource element of IT projects. Although an interest has been established regarding personality traits in the IT literature (White, 1984), there has not been, until now, an empirical study establishing the connection between personality and IT project success factors. This study fills that void in the IT literature. In addition, this study is a contribution to the psychology literature by establishing the Big Five personality traits' ability to effectively travel to the domain of IT; thereby verifying predictability and extending knowledge of personality theory. In addition, this study further establishes the validity of the Big Five as an important tool for personality research and theory.

For practitioners, this study provides a valuable tool to aid in selecting IT team members as well as assigning roles and responsibilities to individuals in the project team. The brief version of the Big Five personality instrument offers a fast and effective method for managers to measure the personality traits of their personnel. Managers should above all be aware that a variety of personality traits is imperative for the success of an IT project. Also, managers should consider that although the impact of personality on project performance is significant, its explanatory power is moderate. Therefore, while it is important to consider personality in making decisions regarding project team member selection and role assignment, personality should not be the only criteria managers use to make these decisions. Managers should also include factors such as experience and intelligence to help guide their project team selection decisions.

Based upon the findings in this study, individuals high in the trait of extraversion would be appropriately placed in roles of monitoring project status, especially in roles of responsibility for the progression of tasks along the project timeline. Their energy, leadership, and motivational attributes are beneficial in keeping workflow moving 
and the project on schedule. Although individuals who are high in the trait of openness to experience were found to have a negative impact on the project schedule, these individuals should not be excluded from the project team. Instead, these individuals may need to be managed differently than other personality types. Their creativity and insight are undoubtedly beneficial, especially in projects that are highly innovative. Such individuals may be wellsuited for roles in creative problem solving and in brainstorming novel solutions. However, such individuals may need to be involved in setting performance goals for their work tasks in order to help them stay on track. In addition, management should openly communicate the importance of keeping the project on schedule and meeting milestone deadlines. At last, conscientious individuals play a key role in project quality. Such individuals may be well suited for assuming responsibilities related to quality control. However, those who are high on the conscientious trait may need to be aware of goals regarding the project schedule so that they do not sacrifice precious time in order to achieve quality perfection. Once again, managers may want to involve these individuals in setting performance goals in which the importance of deadlines is apparent.

The traits of agreeableness and emotional stability, though not found to be significant in this study, should still be considered as playing important roles in the overall IT project endeavor. Although agreeableness was not hypothesized to have a significant influence on project schedule or quality, mangers should be aware that individuals high on the agreeableness trait will be instrumental in keeping harmonious relationships between the diverse set of individuals found in project teams. According to the literature, agreeable individuals will be effective in interpersonal facilitation (Hurtz and Donovan, 2000). In addition, the other personality trait that was not found to be significant in this study, emotional stability, should also be considered an important personality type in the project team. According to the literature, these calm and stable individuals may aid in team conflict resolution (Moberg, 2001). In addition, those who are emotionally stable likely have other important contributions to the project team. The relationship between emotional stability and project success may be more complex than what is understood at the current time in that the relationship may be non-linear and/or there may be intervening variables that further explain how emotional stability influences project outcomes (Salgado, 1997). Therefore, it is important to note that those who are emotionally stable may still play an important role in the project team and should potentially be assigned responsibilities related to conflict management.

\section{LIMITATIONS AND FUTURE RESEARCH}

One of the limitations of this study is the self-reported perceptions of project outcomes (quality and schedule). Self-reported measures may be subject to bias and may be influenced by the perceptual differences that various individuals might have of the project outcomes. Nonetheless, merits of using perceptual measures of project outcomes have been well established and utilized in other research studies (Barki and Hartwick, 2001). Furthermore, this study is an initial investigation into the role of team member personality traits within an information systems development project. Now that it has been identified that in fact personality traits do play an influential part in the make-up of project teams, future studies should be conducted that include actual project outcome measures (actual schedule and quality information). It would especially be beneficial to conduct controlled experiments. Perhaps studying IT student projects and manipulating the composition of personality types in each student team would be helpful in isolating best personality type combinations for project team composition. In addition, future research is called for to address potential intervening variables between personality characteristics and project outcomes. For example, what personality states, attitudes, and behaviors might be mediating the relationships between personality traits and project outcomes? Also, are there certain situational factors and/or other personality traits that moderate the relationships tested in this study? Are there moderators that explain why some of the hypothesized relationships were not significant, such as the relationship between conscientiousness and schedule? One potential moderator worth investigating would be goal perceptions. For example, if a conscientious individual was not aware of the project's time goals, such as specific milestone deadliness, then their natural tendency may be to focus on quality. However, if that same conscientious individual was aware of the deadlines for each project milestone then the same individual may actually prove to be more driven to stay within the schedule. All in all, this study has provided the foundation for a plethora of future research endeavors to help understand the connection between team member personalities and IT project outcomes. 


\section{CONCLUSION}

The current study has extended theoretical and practical knowledge regarding personality traits as predictors of IT project success in terms of schedule and quality assessments. The individual personality trait of extraversion was associated with keeping the project within its scheduled timeline, while the trait of openness to experience was associated with the project falling behind schedule. At last, conscientiousness was found to have a positive influence on project quality.

\section{APPENDIX A - MEASUREMENT SCALES}

\section{Project Outcome Measures}

1. Compared to its estimated schedule, the project is currently running (behind schedule, on schedule, ahead of schedule)

2. In general, I think that the quality of this project so far to be (low quality, high quality)

Project outcome measures were adapted from Barki and Hartwick (2001). Each question was evaluated on a 7-point Likert scale.

\section{The Big Five Measures}

I see myself as:

1. Extraverted, enthusiastic.

2. Critical, quarrelsome.

3. Dependable, self-disciplined.

4. Anxious, easily upset.

5. Open to new experiences, complex.

6. Reserved, quiet.

7. Sympathetic, warm.

8. Disorganized, careless.

9. Calm, emotionally stable.

10. Conventional, uncreative.

The Big Five measures were utilized from Gosling, Rentfrow, and Swann (2003). Each item was evaluated on a 7-point Likert scale and anchored by: Strongly Disagree, Strongly Agree. The scale scoring is as follows ("R" demotes reverse-scored items): Extraversion: 1, 6R; Agreeableness: 2R, 7; Conscientiousness: 3, 8R; Emotional Stability: 4R, 9; Openness to Experiences: 5, 10R. 


\section{REFERENCES}

1. Barki, H., \& Hartwick, J. (2001). Interpersonal conflict and its management in information systems development. MIS Quarterly, 25(2), 195-228.

2. Barrick, M. R., \& Mount, M. K. (1991). The big five personality dimensions and job performance: A metaanalysis. Personnel Psychology, 44(1), 1-26.

3. Calisir, F., \& Gumussoy, C. A. (2005). Determinants of budget overruns on IT projects. Technovation, 25(631-636).

4. Dirks, K. T., \& Ferrin, D. L. (2002). Trust in leadership: Meta-analytic findings and implications for research and practice. Journal of Applied Psychology, 87(4), 611-628.

5. Donnellan, M. B., Oswald, F. L., Baird, B. M., and Lucas, R. E. (2006). The Mini-IPIP scales: Tiny-YetEffective measures of the Big Five factors of personality. Psychological Assessment, 18(2), 192-203.

6. Gardiner, P. D., \& Stewart, K. (2000). Revisiting the golden triangle of cost, time, and quality: The role of NPV in project control, success, and failure. International Journal of Project Management, 18(4), 251.

7. Gosling, S. D., Rentfrow, P. J., \& Swann Jr., W. B. (2003). A very brief measure of the Big-Five personality domains. Journal of Research in Personality, 37, 504-528.

8. Hartman, Deborah. (2006). Interview: Jim Johnson of the Standish Group. INFOQ Website: http://www.infoq.com/articles/Interview-Johnson-Standish-CHAOS

9. Hurtz, G. M., \& Donovan, J. J. (2000). Personality and job performance: the big five revisited. Journal of Applied Psychology, 85(6), 869-879.

10. Judge, T. A., Heller, D., \& Mount, M. K. (2002). Five-factor model of personality and job satisfaction: A meta-analysis. Journal of Applied Psychology, 87(3), 530-541.

11. Judge, T. A., Martocchio, J. J., \& Thoresen, C. J. (1997). Five-factor model of personality and employee absence. Journal of Applied Psychology, 82(5), 745-755.

12. Kline, P. (2000). Handbook of Psychological Testing. London, Routledge.

13. Lim, B.-C., \& Ployhart, R. E. (2004). Transformational leadership: Relations to the five-factor model and team performance in typical and maximum contexts. Journal of Applied Psychology, 89(4), 610-621.

14. McCrae, R. R., \& Costa, P. T. J. (1987). Validation of the five-factor model of personality across instruments and observers. Journal of Personality and Social Psychology, 52, 81-90.

15. Moberg, P. J. (2001). Linking conflict strategy to the five-factor model: Theoretical and empirical foundations. The International Journal of Conflict Management, 12(1), 47-68.

16. Rammstedt, B. and John, O. P. (2007). Measuring personality in one minute or less: A 10-item short version of the Big Five Inventory in English and German. Journal of Research in Personality, 41, 203-212.

17. Salgado, J. F. (1997). The five factor model of personality and job performance in the European community. Journal of Applied Psychology, 82(1), 30-43.

18. Schwalbe, K. (2005). Information Technology Project Management (Fourth ed.). Boston, MA: Thompson Course Technology.

19. TATA (2007). TATA Consultancy Services Website: http://www.tcs.com/NAndI/default1.aspx?Cat_Id=102\&DocType=327\&docid=1577.

20. Seibert, S. E., \& Kraimer, M. L. (2001). The five-factor model of personality and career success. Journal of Vocational Behavior, 58, 1-21.

21. Standish Group (2006). 2006 Chaos Report.

22. Wateridge, J. (1998). How can IS/IT projects be measured for success? International Journal of Project Management, 16(1), 59-63.

23. Watson, D. C. (2001). Procrastination and the five-factor model: A facet level analysis. Personality and Individual Differences, 30(1), 149-158.

24. White, K. B. (1984). MIS project teams: An investigation of cognitive style implications. MIS Quarterly, 95-101.

25. Wood, S.A., and Hampson, S. E. (2005). Measuring the Big Five with single items using a bipolar response scale. European Journal of Personality, 19, 373-390. 
NOTES 